\title{
A RECONFIGURAÇÃO DA IDENTIDADE CULTURAL EM PRECISAMOS DE NOVOS NOMES, DE NOVIOLET BULAWAYO
}

\author{
Shirley de Souza Gomes Carreira ${ }^{1 \times}$ \\ Universidade do Estado do Rio de Janeiro, Rio de Janeiro, Rio de Janeiro, Brasil
}

\section{Resumo}

O objetivo deste artigo é analisar a reconfiguração da identidade cultural da protagonista de Precisamos de novos nomes, de Noviolet Bulawayo. Nesse romance de formação, a autora narra a história de Darling, desde a sua infância, em Harare, no Zimbábue, até tornar-se adulta, na condição de imigrante nos Estados Unidos. O romance tem como pano de fundo a crise econômica, política e social que assolou o país no período pós-independência, agravada pela disseminação da AIDs. Como muitos compatriotas, a protagonista constrói uma imagem utópica da América, que, anos mais tarde, se desfaz ante as dificuldades enfrentadas pelos imigrantes em solo norte-americano.

Palavras-chave: Imigração; Identidade; Aculturação.

\section{THE RECONFIGURATION OF CULTURAL IDENTITY IN WE NEED NEW NAMES, BY NOVIOLET BULAWAYO}

Abstract

The aim of this article is to analyze the reconfiguration of the cultural identity of the protagonist of We Need New Names, by Noviolet Bulawayo. In this coming-of-age novel, the author narrates Darling's story from her childhood, in Harare, Zimbabwe, until she became an adult, as an immigrant in the United States. The novel's background is the economic, political and social crisis that plagued the country in the post-independence period, aggravated by the spread of AIDs. Like many compatriots, the protagonist builds a utopian image of America, which, years later, melts away due to the difficulties faced by immigrants on American soil.

Keywords: Immigration; Identity; Acculturation.

"Doutora em Literatura Comparada (UFRJ) com estágio Pós-Doutoral em Literaturas de Língua Inglesa (UERJ). Professora Adjunta do Departamento de Letras da Faculdade de Formação de Professores da Universidade do Estado do Rio de Janeiro. Docente permanente do Programa de Pós-Graduação em Letras e Linguística da UERJ. Rio de Janeiro, Brasil. E-mail: shirleysgcarr@gmail.com. ORCID: https://orcid.org/0000-0002-8787-823. 
Conheces o nome que te deram, não conheces o nome que tens. José Saramago

\section{Por que precisamos de novos nomes?}

A independência das ex-colônias em África deu-se de modo traumático, pois, ao se estabelecerem como estados-nação, esses países enfrentaram conflitos internos e passaram por fases de instabilidade política e econômica, das quais as populações locais foram as maiores vítimas. Os conflitos armados foram, em grande parte, responsáveis por uma espécie de êxodo empreendido por aqueles que buscavam melhores condições de vida e maior segurança. Esse trânsito de pessoas intensificou a produção de obras literárias que tematizam os movimentos migratórios, expondo aspectos contextuais que lhes são inerentes, como o choque cultural e o processo de adaptação a uma nova terra; e, não raramente, são inspiradas pelas experiências pessoais de seus autores.

O vínculo do homem com o "lugar antropológico"1 (AUGÉ, 1994, p. 51) é sedimentado por saberes compartilhados e interrelações que colaboram para a definição das identidades e do sentido de pertencimento, uma vez que o lugar é também o espaço da ancestralidade. Não é, portanto, estranho que as representações desse vínculo permeiem as narrativas sobre a migração.

$\mathrm{Na}$ eventualidade do deslocamento territorial, do desenraizamento, é a memória que mantém vivo o elo com a terra natal. Entretanto, a desterritorialização ${ }^{2}$ pressupõe uma reterritorialização, ou seja, um processo de reconstrução do "lugar" em outro espaço, que não corresponde, na realidade, a uma tentativa de reproduzir o espaço original, mas a um modo de refazer o território na pátria de acolhimento; de estabelecer novos elos e reconfigurar a identidade. Em algumas circunstâncias, o retorno à terra natal é impossível, produzindo uma fratura incurável (SAID, 2003, p.46), responsável por um permanente sentimento de perda e nostalgia, frequente nos romances sobre imigrantes.

Entre os escritores com raízes africanas que escrevem em língua inglesa, cujas obras abordam a migração, há que destacar Chimamanda Nogzi Adichie, Dinaw Mengestu, Teju Cole, Taiye Selasi e Noviolet Bulawayo. A fim de exemplificarmos como a ficção promove representações da reconfiguração das identidades culturais nos processos migratórios, examinaremos o romance Precisamos de novos nomes (2014), de Noviolet Bulawayo, escritora nascida no Zimbábue, em 1981, e atualmente radicada nos Estados Unidos.

Precisamos de novos nomes, obra de estreia da autora, recebeu vários prêmios e alçou-a repentinamente à condição de finalista ao Man Booker Prize de 2013. Em várias entrevistas concedidas à época do lançamento do livro, Bulawayo explicou o título atribuindo-o a duas razões igualmente significativas: primeiramente, ao fato de que, em seu país, é comum que as pessoas sejam identificadas por meio de diferentes nomes, e, em segundo lugar, ao processo de construção da própria identidade, não apenas experimentado pelos imigrantes, mas também 
pelos países, que, como o Zimbábue após a independência, ainda tentam definirse enquanto nação. ${ }^{3}$

Um aspecto relevante do romance é o fato de que ele se caracteriza como uma apropriação contemporânea do romance de formação. Termo criado pelo filologista alemão Johann Karl Simon Morgenstern, no século XIX, o Bildungsroman designa "um tipo de romance que acompanha o desenvolvimento da mente e do caráter do protagonista desde a infância até a idade adulta, em meio a uma turbulenta busca da identidade e do seu papel no mundo" (ADATIYA, 2016, p. 48) e tem em Os anos de aprendizado de Wilhelm Meister (1795), de Goethe, seu modelo.

Se o romance de Goethe coadunava-se com o ideal de criar uma literatura que expressasse o "espírito alemão", centrando-se em uma personagem masculina e burguesa, as demais apropriações do modelo, dentre elas A portrait of the artist as a young man, de James Joyce, configuram expressões de contextos sócio-político-culturais próprios da cultura em que foram produzidas. Entretanto, como aponta Cristina Ferreira Pinto, ${ }^{4}$ quando a personagem é feminina, geralmente o ocorre sob a tutela masculina. Nesse sentido, podemos afirmar que Precisamos de novos nomes é uma apropriação contemporânea, uma vez que até mesmo o paradigma do bildungsroman feminino é subvertido.

A protagonista é Darling, uma menina de dez anos, que, em meio à pobreza da comunidade do Paraíso, um aglomerado de barracos de zinco, na capital do Zimbábue, tenta viver a sua infância com alegria, ainda que consciente da diferença entre a sua vida e aquela dos brancos, moradores de bairros vizinhos. Em sua inocência, acalenta o sonho de ir para a América, onde, acredita, não sentirá mais fome, terá uma vida confortável e muito mais feliz. Muitos anos mais tarde, Darling vai para os Estados Unidos, onde passa a viver com a tia, em Detroit, e enfrenta uma crise identitária que será o cerne do nosso trabalho.

A identidade cultural (HALL, 2003) é o conjunto vivo de relações sociais e patrimônios simbólicos historicamente compartilhados que estabelecem a comunhão de determinados valores entre os membros de uma sociedade. Nos movimentos migratórios, essas relações se fragilizam e, mediante a necessidade de adaptação à nova terra, um processo de aculturação (BERRY, 2004) se inicia e atua de modo transformador sobre as identidades. O romance de Bulawayo promove uma representação da reconfiguração identitária da protagonista. O novo nome a que o título do romance se refere está, portanto, associado a uma nova identidade, que surge híbrida, como fruto do contato entre culturas.

\section{Um paraíso às avessas: $o$ mundo de antes}

O primeiro capítulo do romance apresenta seis crianças esfomeadas, que se dirigem a Budapeste, uma cidade próxima à comunidade miserável em que vivem, denominada Paraíso, para roubar goiabas. À medida que caminham, falam de suas expectativas de deixar o país e reconstruir a vida em outro lugar. Por meio do olhar da protagonista, é desvelado ante o leitor um panorama do contexto 
sócio-político-cultural em que a história se desenrola. No Paraíso, a pobreza dos barracos, tão pequenos e baixos que um adulto não consegue ficar de pé dentro deles, alinha-se com as vestes esfarrapadas das personagens, sempre descalças, e a fome constante:

Estamos a caminho de Budapeste: o Bastard e a Chipo e o Godknows e a Sbho, o Stina e eu. Estamos a caminho mesmo não tendo licença para atravessar a estrada Mzilikazi, mesmo que o Bastard devesse estar a tomar conta da sua irmãzinha Fraction, mesmo que a Mãe vá me matar se descobrir; mesmo assim a gente vai. Tem goiabas para roubar em Budapeste, e neste momento eu morreria por umas goiabas. Nós não comemos esta manhã e é como se alguém tivesse apanhado uma pá e cavado meu estômago, tirando tudo lá de dentro. (BULAWAYO, 2014, p.9)

Embora o romance não mencione explicitamente o Zimbábue, nem o desastroso governo de Robert Mugabe, ${ }^{5}$ essa identificação está implícita, como reforça a autora em uma entrevista concedida a DW.com. ${ }^{6}$ No romance, a miséria, assim como a violência, está sempre presente e, de certo modo, quase naturalizada, dada a sua constância, e Bulawayo explica que a sua opção por uma narradora infantil, que não existia na primeira versão do romance, deveu-se à necessidade de dar um tom menos irado à narrativa:

[...] as primeiras versões do romance, na verdade, nomeavam o Zimbábue, e se reportavam a Mugabe. Não estavam na voz de Darling, mas na voz de um camponês mais velho. Então você pode imaginar que era muito político. Havia muito de uma NoViolet irritada lá. Repentinamente, isso começou a "matar" a história, e eu tive que recuar e introduzir uma narradora jovem e deixar a política de fora. Nesta versão, acho que a política ainda está lá, mas sem bloquear a história. (Tradução nossa)

Bulawayo nasceu um ano após a antiga Rodésia ter conquistado a sua independência, em 1980, e dezoito anos depois emigrou para os Estados Unidos, retornando somente em 2017. A primeira parte do romance aborda ficcionalmente o período de declínio do governo de Mugabe, após a reforma agrária que consistiu na retirada das terras de agricultores brancos, que foram entregues a membros do seu partido, gerando a queda da produção agrícola que levou à hiperinflação e à fome.

Nesse cenário de miséria, as crianças do romance são forçadas a amadurecer. Entre elas, Chipo, uma menina de onze anos, está grávida, vítima de um estupro perpetrado pelo próprio avô. Sempre silenciosa, traz em si a marca da violência que parece estar em toda parte. Nenhuma das crianças frequenta mais a escola, pois os professores migraram, assim como o pai de Darling, que fora para a África do Sul e não retornara. A precariedade da existência faz com que elas desenvolvam certa insensibilidade diante de situações drásticas. No retorno de Budapeste, por exemplo, elas deparam com uma mulher enforcada em uma árvore e apressam-se a retirar-lhe os sapatos, para vendê-los e comprar pão. 
As mazelas sociais são expostas, uma a uma. A progressiva desvalorização da moeda é emblematizada pela imagem de Mother of Bones a contar diariamente o dinheiro sem valor contido em uma mala. A ação perniciosa de falsos líderes religiosos é personificada na figura estapafúrdia do Profeta Revelations Bitchington Mborro, que não apenas explora os já miseráveis fiéis, como também usa a religião para abusos sexuais:

O Profeta Revelations Bitchington Mborro reza pela mulher desse jeito, deitado em cima dela e chamando Jesus e gritando versículos da Bíblia. Coloca as mãos na barriga dela, nas suas coxas, em seguida coloca as mãos naquele lugar dela e começa a esfregar, rezando muito, como se houvesse algo de errado ali. (BULAWAYO, 2014, p.42)

Segundo Ngoshi (2016, p. 56), Bulawayo promove uma carnavalização ao criar a personagem do profeta, cujo sobrenome, sem um dos "r"s, significa "falo" no dialeto Shona.

A expansão da AIDS em África é igualmente representada no romance, não só pela mulher que opta por enforcar-se a definhar até a morte, mas também pelo pai de Darling, que, contaminado, retorna inesperadamente a casa. Na esperança da cura, a mãe de Darling recorre ao profeta. Este, após afirmar que o espírito do avô falecido, que estava no corpo de Darling, havia passado para o corpo do pai, cobra quinhentos dólares para fazer o serviço, mas, na falta destes, "euros também servem" (BULAWAYO, 2014, p. 91).

Em meio à pobreza e à incerteza do futuro, os moradores do Paraíso recorrem às suas crenças em busca de alento:

Passamos pelos barracos pequeninos, um após outro, barracos amontoados como fatias de pão quente. Não uso sapatos porque agora eles estão pequenos e os outros fabricados na China que a Mãe me trouxe da fronteira se desmancharam, então ando com cuidado e levanto os pés para evitar as coisas no caminho [...] quando passamos pelas pessoas em pé na fila do lado de fora do barraco de Vodloza, a Mother of Bones só acena, aqui ela não pode gritar, porque é a casa de um curandeiro [...] uma grande placa branca diz em palavras vermelhas, em inglês: VODLOZA O MAIS BOM CURADOR EM TODO O PARAIISO E ARREDORES RESOLVE TODAS AS COISAS DEFICIS QUE VOCÊ PODE ENCONTRAR EM SUA VIDA, FEITIÇOS, MALDIÇÕES, AZAR, ESPOSAS VADIAS, FALTA DE FILHOS, POBREZA, FALTA DE EMPREGO, AIDS, LOUCURA, PÊNIS PEQUENO, INFERTILIDADE, EPILEPSIA [...] AZAR PARA CONSEGUIR VISTOS ESPECIALMENTE PARA OS EUA[...] POR FAVOR, PAGAMENTOS SOMENTE EM FOREX. (BULAWAYO, 2014, p. 32).

Nesse paraíso às avessas, as crianças buscam entreter-se como podem e, em um jogo intitulado “jogo dos países”, é possível perceber como os desejos de cada uma se projetam. A percepção da condição de subalternidade, inerente ao local onde vivem e ao modo de vida de seus habitantes, faz com que elas entrem em conflito, buscando escolher os países desenvolvidos, que inocentemente designam como "país-país", em oposição aos demais: "se tiver sorte, como hoje, con- 
sigo ser os EUA, que é um país-país; quem não sabe que os EUA são o grande babuíno do mundo?" (BULAWAYO, 2014, p. 49).

A primeira parte do romance contém também a chave para a interpretação do título. As personagens são nomeadas, em sua maioria, a partir de apelidos, como Bastard, Godknows e Mother of Bones. No sexto capítulo, por receio de que Chipo morra em consequência do parto e por acharem que a barriga atrapalha as brincadeiras, as crianças decidem que devem ajudá-la a livrar-se da gravidez, provocando um aborto. A situação, embora séria, é emblemática, pois revela o julgamento das crianças acerca da própria identidade. O parâmetro que têm é o do seriado Plantão médico, e, assim, chegam à conclusão de que, para praticar o aborto de modo adequado, necessitam de novos nomes, passando a utilizar os nomes dos médicos do seriado.

Em uma entrevista concedida a Sabine Pechel, em 2015, Bulawayo explica o sentido do título:

Escrevi o romance em um momento específico da história do meu país. História recente, devo dizer, quando o país estava se desfazendo, devido ao fracasso da liderança. E dizendo "precisamos de novos nomes", eu estava falando sobre a necessidade de nós, como pessoas, reimaginarmos, repensarmos, repensarmos nosso caminho, pensarmos sobre aonde estávamos indo. Precisávamos de novas formas de ver as coisas, novas maneiras de fazer as coisas, novas lideranças. Foi basicamente uma chamada para renovação. Mas não deve limitar-se ao Zimbábue. Eu acredito que é possível traduzir-se além das fronteiras. ${ }^{7}$ (Tradução nossa)

Por fim, ainda na primeira parte do romance, as crianças, escondidas em uma árvore, presenciam a invasão e depredação de uma casa pertencente a um casal branco, que, em seguida, é levado por um grupo de ativistas negros. Cabe a Darling, a que melhor se expressa em inglês dentre as crianças, atender ao telefone que toca inesperadamente e comunicar à filha do casal o que acontecera a seus pais. O olhar da pequena Darling expõe, de modo velado, as contradições e os conflitos sociais e políticos do mundo em que vive, pois, sendo ainda uma criança, ela não compreende efetivamente a dimensão dos eventos que descreve.

A separar as duas partes do romance há o capítulo intitulado "Como eles foram embora", escrito como um monólogo, em um tom de lamento e prenunciando não apenas as adversidades narradas na segunda parte, mas também a transformação identitária da protagonista:

Olhe para os filhos da terra indo embora aos bandos, deixando sua terra com feridas que sangram em seus corpos e susto em seus rostos e sangue em seus corações e fome em seus estômagos e tristeza em seus passos. Deixando suas mães e pais e filhos para trás, deixando seus cordões umbilicais debaixo do solo, deixando os ossos de seus antepassados na terra, deixando tudo o que os torna quem e o que são, indo embora, pois não é mais possível ficar. Eles nunca mais serão os mesmos, porque você simplesmente não tem como ser o mesmo depois que deixa pra trás quem 
e o que você é, você simplesmente não tem como ser o mesmo (Grifo nosso) (BULAWAYO, 2014, p. 132).

\section{Destroyedmichygen: o mundo de agora}

Quando ainda estava em seu país, Darling costumava discutir com Bastard sempre que este criticava o seu desejo de ir para os Estados Unidos, que ela denominava "minha América". Animadamente, referia-se à cidade de Detroit, em que sua tia Fostalina vivia, como Destroyedmichygen. A palavra, "quase homófona de Detroit, Michigan", como explica a nota à edição em português (BULAWAYO, 2014, p. 49), evoca o fato de que Detroit é considerada uma das cidades mais decadentes dos EUA, daí a substituição de Detroit por “destroyed”. O trocadilho, de certa forma, antecipa a percepção que Darling terá do local onde passará a viver. A distância entre o lugar idealizado e o lugar real faz com que o choque cultural seja muito mais intenso. No capítulo que introduz a segunda parte do romance, Darling recorda-se nostalgicamente de seu país e descreve o impacto que lhe causam o frio e a neve: "É um frio que parece querer matar, como se dissesse, com sua neve, que você devia voltar para o lugar de onde veio" (2014, p. 133). Esse sentimento de inadequação gerado pelo clima aumenta pela falta de identificação com a família da tia e pela estranheza ante os hábitos dos norte-americanos:

Se estivesse em casa eu sei que não ficaria sem sair por que uma coisa chamada neve estava me impedindo de ir lá fora viver a vida. Talvez eu e a Sbho e o Bastard e a Chipo e Godknows e o Stina estaríamos em Budapeste, roubando goiabas. Ou estaríamos brincando de encontrar Bin Laden ou do jogo dos países ou de queimada. Mas por outro lado não teríamos comida suficiente, e é por isso que vou tolerar ficar na América aguentando a neve; tem comida para comer aqui [...] mas tem horas que não importa quanta comida eu coma, vejo que a comida não faz nada por mim, como se estivesse com fome pelo meu país e nada fosse resolver isso. (BULAWAYO, 2014, p.138)

Por uma contingência, os tios de Darling são obrigados a mudar de cidade e a dificuldade de adaptação torna-se ainda maior, uma vez que ela passa a ser alvo de bullying:

Quando cheguei a Washington, queria morrer. As outras crianças implicavam comigo por causa do meu nome, do meu sotaque, do meu cabelo, do jeito que eu conversava ou dizia coisas, do jeito que eu me vestia, do jeito que eu ria. Quando implicam com você por causa de alguma coisa, primeiro você tenta consertar essa coisa para que as implicâncias parem, mas aquelas crianças malucas implicavam comigo por tudo, até mesmo as coisas que eu não tinha como mudar, e isso continuou acontecendo e continuou acontecendo até que no fim simplesmente tudo parecia errado dentro da minha pele, do meu corpo, das minhas roupas, da minha língua, da minha cabeça. (BULAWAYO, 2014, p. 149) 
A passagem citada mostra que o sentimento de inadequação faz com que Darling deseje ser diferente do que é, ainda que custe o apagamento da própria identidade, pois não suporta o peso da diferença e da discriminação. O bullying que sofre na Washington Academy, escola que passa frequentar, diminui apenas quando um aluno novo, Tom, passa a ser o alvo da implicância dos colegas, fato que o leva ao suicídio.

O estigma de imigrante agrava-se pelo fato de Darling ser africana. Em uma série de conferências intitulada TED talks, a escritora nigeriana Chimamanda Ngozi Adichie alerta para o perigo das generalizações, de "uma hístória única", pois, assim como Darling, teve de defrontar-se com uma visão uniformizadora da África, que a pressupõe como um único lugar, ignorando as múltiplas culturas e etnias, bem como um lugar emblematizado por imagens de catástrofes, miséria e violência.

Ao ser interpelada por uma norte-americana, Darling fica constrangida, pois desconhece o que ocorre em outros países africanos:

A África é bonita, ela diz, continuando com sua palavra favorita. Mas não é terrível o que está acontecendo no Congo? Um horror. Agora ela me olha com essa cara ferida. Não sei o que fazer ou dizer, então finjo uma tosse comprida só para preencher o silêncio. Meu cérebro está correndo por toda parte e pulando cercas agora, tentando lembrar o que exatamente está acontecendo no Congo, porque acho que estou confundindo com outro lugar, mas o que posso ver nos olhos da mulher é que é sério e importante e eu deveria saber, então por fim eu digo, Sim, é terrível o que está acontecendo no Congo. (BULAWAYO, 2014, p. 158-159)

Quando ainda vivia no Paraíso, fotógrafos da CNN e da BBC haviam tirado fotos dela. Fotos que, provavelmente, foram divulgadas em reportagens ou documentários, mas em nenhum momento perguntaram seu nome. Essa passagem do romance demonstra como a mídia internacional reifica o sujeito subalterno, como o destitui de sua individualidade, para torná-lo apenas símbolo de tragédias coletivas. Essa sensação de invisibilidade agrava-se na segunda parte do romance.

Apesar da opressão cotidiana, Darling não encontra apoio na família. Fostalina tem uma dupla jornada de trabalho, em um hospital e em uma casa de repouso, e, nas horas vagas, dedica-se inteiramente a tentar obter uma melhor forma física, fazendo exercícios extenuantes diante da TV. Seu marido, Kojo, quando não está a reclamar da obsessão da esposa, assiste a partidas de futebol. TK, primo de Darling, é um adolescente obeso, agressivo e pouco sociável.

É com espanto que Darling observa a tia que, mesmo sendo magra, deseja emagrecer ainda mais e "logo vai começar a parecer com os ossos do Pai, afogado ali na cama, esperando para morrer" (BULAWAYO, 2014, p.139), em contraste com TK, que engorda cada vez mais. O comportamento de Fostalina, cada vez mais próximo do modus vivendi norte-americano, é completamente estranho a uma criança que vem de um país onde o alimento é escasso. 
Por serem de países diferentes, Fostalina e Kojo volta e meia praguejam em seus próprios idiomas, e Darling assiste a tudo indagando a si mesma como será quando retornar ao seu país:

Stina também disse que deixar o seu país é como morrer, e quando você retorna é como um fantasma perdido voltando pra terra, andando por aí com um olhar ausente. Não quero ser isso quando voltar ao meu país, mas na verdade não sei, porque será que o Paraíso vai estar lá quando eu voltar? (BULAWAYO, 2014, p.143)

A reflexão de Darling sobre a fala do amigo demonstra que, mesmo com a possibilidade de retorno, a transformação sofrida pelo imigrante faz com que o sentido de pertencimento seja rasurado. O Paraíso que ela gostaria de encontrar é o das brincadeiras infantis, que lhe permitiam fantasiar e escapar do mundo real. Entretanto, assim como ela, os amigos de infância também estavam crescendo. Subitamente, ela percebe que talvez não haja para onde retornar.

São muitas as instâncias no romance em que o passado é rememorado, como, por exemplo, na passagem em que, ao comer uma goiaba, esta, como a madeleine de Proust, faz com que empreenda uma viagem no tempo: "como ela entenderia que a cada vez que dou uma mordida na goiaba, eu deixo a casa, Kalamazoo e Michigan, deixo o país, e me encontro outra vez no Paraíso, em Budapeste?" (BULAWAYO, 2014, p. 163).

Assim que chegara aos Estados Unidos, Darling escrevia aos amigos, sem, no entanto, revelar como a América efetivamente se mostrava ante seus olhos:

[...] tomava cuidado para deixar certas coisas de fora também, por exemplo, o clima que era horrível [...] que a casa onde a gente morava não era nem um pouco parecida com as que a gente tinha visto na tevê quando éramos pequenos, como ela não era feita de tijolos mas de tábuas [...] e como quando chovia essas tábuas mofavam e cheiravam mal [...] como nas noites de verão tinha às vezes o pá-pá-pá de tiros na vizinhança [...] como tinha gente pobre que morava na rua, segurando cartazes para pedir dinheiro. Eu deixava essas coisas de fora [...] porque elas me envergonhavam, porque faziam com que a América não se parecesse com a Minha América, aquela com a qual eu sempre tinha sonhado no Paraíso. (BULAWAYO, 2014, p. 167)

Com o tempo, deixara de escrever. A América real, com todo o desencanto que lhe trouxera, exigia esforço para dominar o novo idioma, para adquirir novos hábitos, para forjar uma nova identidade. Segundo Rushdie (1991, p. 277-8), "um migrante, na acepção completa da palavra, sofre, tradicionalmente, uma tripla ruptura: ele perde o seu 'lugar', adota uma língua estrangeira, e se vê cercado de pessoas cujo comportamento e códigos sociais são muito diversos dos seus, e, às vezes, até mesmo ofensivos". Essas rupturas são vivenciadas por Darling com um sentimento de estranheza, incompatível com a sua idealização da América. No capítulo intitulado "Como eles viviam", há outro monólogo, desta vez como uma síntese do que significa ser imigrante nos EUA: 
Como a América nos surpreendeu de início! Se você não estava feliz com o seu corpo, podia ir a um médico e dizer, por exemplo, Doutor, nasci no corpo errado, por favor, me conserte [...] Observamos as pessoas enviando seus pais para longe, para serem cuidados por estranhos [...] Como não estávamos usando nosso idioma, dizíamos coisas que não queríamos dizer; o que realmente queríamos dizer, ficava dobrado dentro de nós [...] pelos vistos e passaportes, imploramos, nos desesperamos, mentimos, nos humilhamos [...] e quando chegamos à América, pegamos os nossos sonhos [...] e os pusemos de lado, não os perseguiríamos [...] não havia escola para nós [...] em vez de estudar, trabalhamos [...] abaixávamos a cabeça porque não éramos mais pessoas, éramos imigrantes ilegais (Grifo nosso) (BULAWAYO, 2014, p.211-213).

Em sua inocência, Darling acreditara na promessa da tia de que em breve voltaria a ver a mãe e os amigos, e, à medida que o tempo passa, percebe que Fostalina tem sempre uma desculpa para a impossibilidade da visita. Só muito tempo mais tarde descobre que, por ser imigrante ilegal, se sair dos Estados Unidos não poderá voltar. E, como tantos outros, cujos pais morreram esperando a volta dos filhos, Darling começa a se acostumar à ideia de que o retorno é impossível.

Muito embora não veja um modelo na tia ou em qualquer outra mulher com quem convive, Darling reconhece que, na América, é possível desconstruir convenções que outrora lhe pareciam imutáveis, como, por exemplo, a visão do tio Kojo, que nascera em Gana, acerca da esposa ideal: "Sabe, no meu país as mulheres cozinham refeições quentes todos os dias para os seus maridos e filhos. E não só isso, elas também lavam e passam e mantêm a casa limpa" (BULAWAYO, 2014, p. 140).

Aos poucos, novos hábitos, e algumas transgressões, como as sessões de filmes pornográficos à tarde, quando os tios estavam trabalhando, vão se incorporando ao seu cotidiano. Segundo Canclini (2007, p. 202), a relocalização "engendra novos espaços, que enfraquecem os laços precedentes" à medida que novas experiências surgem e novos laços vão sendo estabelecidos. No romance, $o$ contato de Darling com a terra natal se resume a conversas com a Mãe via Skype e, eventualmente, com os amigos de infância, que lhe trazem de volta o passado, despertando a saudade. Em uma das vezes em que liga para a Mãe, é Chipo quem atende e lhe diz que a maioria dos amigos partiu, para tentar a vida em outro lugar. Apenas ela ficara, com a filha, a quem havia dado o nome de Darling. Chipo a acusa de ter abandonado o passado e seu país:

Só me diga uma coisa. O que você está fazendo que não está no seu país agora? Por que você fugiu para a América, Darling Nonkululeko Nkala, hein? Por que foi embora? Se é o seu país, você precisa amá-lo e viver nele e não o deixar. Tem de lutar por ele não importa o que aconteça, para consertar as coisas. Diga-me, você abandona a sua casa porque ela está pegando fogo ou procura água para apagar o incêndio? [...] Você foi embora, Darling, querida, você deixou a casa queimando e tem a cara de pau de me dizer, com esse sotaque ridículo que nem tinha antes e que nem combina com você, que este é o seu país? (BULAWAYO, 2014, p.249) 
As palavras que ouve causam-lhe revolta e, em um acesso de ira, atira o computador para longe. Sim, ela tinha saudade de casa, das pessoas que deixara no Paraíso, de um passado que não poderia recuperar, de uma história que não poderia reescrever. Restava-lhe a América, o emprego clandestino, a casa da tia Fostalina, que secretamente traía o marido, a tristeza do tio Kojo, que perdeu a alegria quando o filho se alistou no exército e foi para o Afeganistão, a universidade, que, segundo a tia, é a única maneira de um imigrante se tornar alguém.

\section{À guisa de conclusão}

O romance Precisamos de novos nomes focaliza a reconfiguração identitária da protagonista, resultante de uma negociação entre culturas diferentes. Ao migrar, Darling passa por um processo de reterritorialização, que implica não apenas a superação das rupturas que o migrante sofre com o espaço, o idioma e a cultura natal (RUSHDIE, 1991), mas também a integração à nova cultura. No caso de Darling, esse processo se torna um pouco mais complexo porque ocorre paralelamente à passagem de criança à adolescente. A arquitetura do romance aponta para essas duas fases distintas, que estão associadas a diferentes localidades, o país natal e os EUA.

A primeira parte aborda questões que são inerentes à maioria dos países que passaram pelo processo de descolonização, como conflitos políticos e raciais, o colapso econômico, etc., e demonstra como a população local foi afetada por todos esses acontecimentos. Ao furtar-se a nomear explicitamente o Zimbábue, de certo modo, Bulawayo parece desejar que o país representado no romance possa ser nomeado segundo a experiência e vontade de cada leitor. Desejo este que parece estar simbolicamente sedimentado no jogo dos países, praticado por Darling e seus amigos.

A segunda parte focaliza não apenas a desmistificação da América enquanto espaço da utopia para o imigrante, como também as dificuldades geradas pelo choque cultural e o processo de reconfiguração identitária. Sendo ela mesma uma imigrante, Bulawayo dá às experiências de Darling as cores necessárias à verossimilhança. A distância da família e da terra natal, a barreira linguística e melancolia que ocasionalmente afeta o imigrante fazem parte do inventário de experiências pessoais da autora, para quem "o corpo e a alma do imigrante guardam a memória do seu espaço natal". ${ }^{8}$

Por fim, a opção por uma narradora que o romance acompanha da infância à adolescência permite, conforme já afirmamos anteriormente, que os eventos históricos sejam narrados com o olhar de estranhamento e inquisição de quem não compreende o desenrolar dos fatos, prescindindo de um compromisso com a história oficial. É com esse olhar que Darling desnuda a América, revolve as memórias e se modifica como sujeito, adaptando-se a um novo modus vivendi e, consequentemente, a uma nova cultura. 
Notas

1. O lugar antropológico é a construção concreta e simbólica do espaço que designa um lugar que é identitário, relacional e histórico e, portanto, responsável pelo sentido do pertencimento.

2. Os conceitos de "desterritorialização" e "reterritorialização" foram desenvolvidos por Gilles Deleuze e Felix Guattari e utilizados pela primeira vez em O anti-Édipo (1972) e, posteriormente, em Kafka: por uma literatura menor (1975), Rizoma (1976), Mil platôs - capitalismo e esquizofrenia (1980) e O que é filosofia? (1991)

3. Cf. http://velamag.com/writing-about-women-at-the-margins-an-interviewwith-noviolet-bulawayo/

4. Cf. PINTO, Cristina Ferreira. O Bildungsroman feminino: quatro exemplos brasileiros. São Paulo: Perspectiva, 1990.

5. Segundo presidente do Zimbábue, que esteve no poder de 1987 a 2017.

6. "...the first drafts of the novel were actually naming Zimbabwe, and they addressed Mugabe. The draft was not in Darling's voice, it was in an older peasant's voice. So you can imagine it was very political. There was a lot of an angry NoViolet in there. It started to kill the story after a while, and I sort of had to pull back and introduce a young narrator and also take the politics out of it. In this version I think the politics are still there, but this is not blocking the story". Cf. http://www.dw.com/en/zimbabweanauthor-noviolet-bulawayo-i-like-to-write-from-the-bone/a-18572543.

7. "I wrote the novel at a specific time of my country's history. Recent history, I should say, when the country was coming undone, due to failure of leadership. And by saying "we need new names" I was speaking for the need for us as a people to sort of re-imagine, rethink ourselves, rethink our way, think about where we were going. We needed new ways of seeing things, new ways of doing things, new leadership. It was basically a call for renewal. But it should not be confined to Zimbabwe. I believe you can translate across borders." Cf. http://www. dw.com/en/zimbabwean-author-noviolet-bulawayo-i-like-to-write-from-thebone/a-18572543.

8. Cf. https://digitalcommons.butler.edu/manuscripts/vol80/iss1/53/.

\section{Referências}

ADATIYA, Chirag R. Chapter- 2 The Origin and Development of Bildungsroman Novels. In: ADATIYA, Chirag R. A study of Sudhindra Nath Ghose's tetralogy of novels as bildungsroman. Gujarat: 2016. p. 39-64. Disponível em:

$<$ http://shodhganga.inflibnet.ac.in/handle/10603/125836>. Acesso em: 02 maio 2018.

AUGÉ, Marc. Não-lugares: introdução a uma antropologia da sobremodernidade. Trad. Lúcia Mucznik, Bertrand Editora, 1994.

BERRY, John W. Migração, Aculturação e Adaptação. In: Psicologia, E/Imigração e Cultura. SP: Casa do Psicólogo, 2004, p. 29-45.

BULAWAYO, Noviolet. Precisamos de novos nomes. Trad. Adriana Lisboa. São Paulo: Biblioteca Azul, 2014.

. Zimbabwean author NoViolet Bulawayo: 'I like to write from the bone'. [15 jul 2015]. Entrevista concedida a Sabine Peschel. Disponível em: https://www. dw.com/en/ zimbabwean-author-noviolet-bulawayo-i-like-to-write-from-thebone/a-18572543 Acesso em: 12 mai. 2018.

CANCLINI, Néstor G. Diferentes, desiguais e desconectados. Rio de Janeiro: Editora da URFJ, 2007. 
DELEUZE, Gilles; GUATTARI, Felix. Mille plateaux: Capitalisme et schizophrénie 2. Paris: Minuit, 1980.

HALL, Stuart. A identidade cultural na pós-modernidade. Tradução de Tomaz Tadeu da Silva e Guacira Lopes Louro. SP: DP\&A Editora, 2003.

HARTSELLE, Christian (2015) Interview with NoViolet Bulawayo. Manuscripts: v. 80, n. 1, Art. 53. Disponível em: <https://digitalcommons.butler.edu/manuscripts/ vol80/iss1/53/> Acesso em 05 de jun. 2018.

NGOSHI, Hazel Tafadzwa. Carnivalising Postcolonial Zimbabwe: The Vulgar and Grotesque Logic of Postcolonial Protest in NoViolet Bulawayo's We Need New Names, UK, Journal of Literary Studies, V. 32, p. 53-69, 2016.

RUSHDIE, Salman. Imaginary Homelands. Essays and criticism 1981-1991.Londres: Granta Books, 1991.

SAID, Edward. Reflexões sobre exílio e outros ensaios. Trad. Pedro Maia Soares. São Paulo: Companhia das Letras, 2003.

SPIVAK, Gayatri Chakravorty. Pode o subalterno falar? Trad. Sandra Regina Goulart de Almeida, Marcos P. Feitosa, André P. Feitosa. Belo Horizonte: Editora da UFMG, 2010.

Recebido em: 10/06/2018

Aceito em: 17/09/2018 